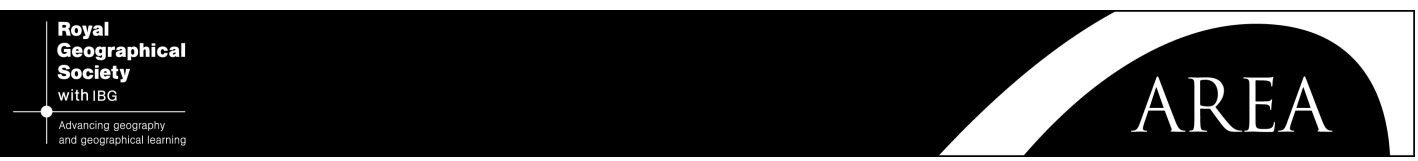

Area (2009) 41.1, 94-106

doi: 10.1111/j.1475-4762.2008.00845.x

\title{
A parsimonious crop-water productivity index: an application to Brazil
}

\author{
Marco P Maneta*, Purnendu N Singh*, Marcelo Torres*, Wesley W Wallender*, \\ Stephen A Vosti ${ }^{\dagger}$, Lineu N Rodrigues ${ }^{\ddagger}$, Luis $\mathrm{H}$ Basso $^{\S}$ and Julie A Young ${ }^{\natural}$ \\ *Department of Land, Air and Water Resources, University of California, Davis, CA 95616, USA \\ Email: pnsingh@ucdavis.edu \\ **Department of Agricultural and Resource Economics, University of California, Davis, CA 95616, USA
}

${ }^{+}$Department of Agricultural and Resource Economics, Center for Natural Resources Policy Analysis, University of California, Davis, CA 95616, USA

${ }^{\ddagger} E$ Embrapa Cerrados, P.O. Box 08223, 73310-970 Planaltina-DF, Brazil

${ }^{\S}$ Embrapa, Semi-Arid Center, P.O. Box 23, 56300-000, Petrolina-PE, Brazil

'Informatics Center, University of California, Davis, CA 95616, USA

Revised manuscript received 13 May 2008

\begin{abstract}
Reducing poverty in rural areas of developing countries requires sustained and sustainable increases in agricultural water productivity. However, aside from traditional measures of precipitation, little is known about water available to farmers or how productively they use it. We present a crop-water productivity index (a ratio of the value of annual crop production to a dimensionless potential water availability index) for large water basins using readily available low-resolution data. The index is transferable, permits direct inter-basin comparisons, and is simple to calculate. We calculate the index for each municipality in the São Francisco river basin in Brazil. No clear patterns linking water availability and value of agricultural output are evident, even though clusters of municipios with high- and low-crop-water productivity emerge, and the former may be useful in guiding policies aimed at increasing water productivity. Finally, analyses of the effects of information uncertainty on the crop-water productivity index suggest that the returns to agricultural investments in certain places in the São Francisco river basin are more risky than others. Improvements in data quality and quantity can help refine estimates of the index and reduce their uncertainty.
\end{abstract}

Key words: water productivity, irrigation, agricultural productivity, crop-water productivity index, water availability index, uncertainty propagation

\section{Introduction}

Two-thirds of the world's poor currently live in rural areas, and increasing rates of growth in agriculture is essential to meeting their food and livelihood security needs (World Bank 2007). In regions where options for expanding cultivated area are limited, agricultural growth must come from increases in crop productivity, while in other regions (primarily in parts of sub-Saharan Africa and South America) expansion of cultivated area is an important second source of growth. In both cases, the primary ingredients for sustainably increasing the returns to land and to labour in rural areas are generally known: investments in transportation infrastructure, water conveyance and irrigation systems, agricultural research, and education are of fundamental importance, and policies that enhance market access, and define 
and protect property rights are also essential (Lee and Barret 2001; Rosegrant et al. 2006). But while these general prescriptions for growth are useful for identifying overall rural development strategies, they are less useful in determining the precise sequencing or location of policy interventions. As population pressure and food prices rise, moving from a generic to a more concrete set of investment options and policy actions becomes urgent.

This paper contributes to the literature on measuring water productivity in agriculture, with special attention paid to the natural movements of water on the landscape. To do so, we construct a crop-water productivity index $(C W P I)$ using readily available data in the São Francisco river basin in Brazil. The proposed methodology is a tool to perform large extent, low resolution spatial analysis to identify areas and spatial patterns of low and high agricultural productivity. This may help identify areas for potential policy action. Once these areas have been identified, a more detailed local high resolution analysis is needed to gain more insight on the specific conditions of the area.

Crop-water productivity indices have been constructed and used for some time. Historically such indices were generally defined as the ratio of a measure of crop production (such as yield, dry matter production, nutritional value or economic value) to a measure of water available to or used in agriculture, such as crop evapotranspiration (Kassam and Smith 2001; Zwart and Bastiaanssen 2004), net water inflows, applied water via irrigation systems, or available water from precipitation. For example, one CWPI (Molden 1997) uses crop yield divided by the volume of water consumed by that crop. Cropwater productivity indices are commonly used to compare the agricultural performance (an implied measure of efficiency) of different regions at different times, especially in irrigated areas at the field or farm level (Abdullaev and Molden 2004; Ahmad et al. 2004; Zwart and Bastiaanssen 2004). CWPI have also been calculated at much larger spatial extents, ${ }^{1}$ but these efforts are usually limited by data availability and quality (especially in the context of frontier areas in developing countries), although the use of satellite remote sensing is increasing the spatial extent as well as the spatial resolution of the available data (e.g. Bastiaanssen 1999; Lobell et al. 2003). Regardless of the spatial extent and resolution adopted, these indices or ratios all focus on the amount of water actually used to produce crop output, but they are silent on the issue of the extent to which potentially available water is put to use in agriculture. To capture this important relationship between the stock of available water at a given location and the proportion of that stock used in agriculture, a different sort of index is needed. This paper proposes such an index.

\section{Objective}

With the goal of developing a CWPI that is based on easily available or easily computed estimates of the value of crop production and a measure of potential water availability, a new water availability index (wai) is defined. The proposed CWPI ratio uses wai as its denominator and the value of crop production as its numerator. Data from the São Francisco river basin in Brazil are used to calculate the index and its sensitivity, and both are used to demonstrate spatial variation in the degree to which available water is being used for agriculture.

\section{Water availability index (wai)}

Several candidate indices exist for measuring potential water availability. A series of topographic indices that predict the spatial distribution of runoff, soil moisture and elevation of groundwater tables or the depth of saturated areas have been developed (Beven and Kirkby 1979; Hjerdt et al. 2004; O'Loughlin 1981), and these indices are commonly used as proxies for water input in analysing environmental issues such as predicting the size of wetlands at continental extent (Merot et al. 2003), soil moisture distribution at varying spatial resolutions (Western et al. 1999), and soil characteristics (Florinsky et al. 2002; Merot et al. 1995), all with varying degrees of success. The proposed water availability index (wai) is a spatially distributed index that is proportional to the potentially available water at a given location. As defined, the proposed index can be calculated for large basins using low-resolution data. The unforced conditions imply the absence of human interventions that affect natural flows (e.g. dams), or strong natural discontinuities such as sharp changes in the topography or land cover that may have strong impacts on the hydrologic regime. The proposed index is an extension of the concept introduced by Beven and Kirkby (1979) which is widely used in hydrology as a measure proportional to the likelihood of a given parcel of land being saturated and producing saturation-excess runoff. The Beven and Kirkby (1979) index is correlated with soil moisture over a range of spatial resolutions, and hence explains (among other things) 
a significant part of observed variations in soil moisture during wet periods when spatial units of analysis are hydrologically connected (Gómez-Plaza et al. 2001; Western et al. 1999).

Under unforced conditions, climatic and topographic factors have strong influences on the amount of surface-, root zone- and groundwater available at a given location at a given time. Topography is recognised as a strong driving force for water movement and water redistribution in the landscape (Dunne and Leopold 1978; Hewlett and Troendle 1967). On an annual basis, the main input components of the water mass balance at a given point are precipitation (vertical component) and inflow (horizontal component) from upstream areas, whereas the main vertical and horizontal outputs are atmospheric demand and outflow to downstream areas, respectively. It is assumed here that water infiltrated into the groundwater system is directly related to available water at the location and is directly captured in the wai measure. While high-resolution, spatially distributed information on annual precipitation and potential evapotranspiration is relatively easy to obtain for large basins from global databases, high-quality information on annual inflows and outflows at the same high-resolution spatial coverage throughout the spatial extent of interest is generally much more difficult to obtain. To generate the required information on annual inflows and outflows, for each spatial unit of observation we use the size of the upstream catchment area and the local ${ }^{2}$ slope to generate estimates of these flows at that point. We assumed that the upstream area draining into a given pixel is proportional to the inflow, and that the local slope at a given pixel determines the outflow as it provides the momentum for the outflow. With estimates of inflow and outflow discharge at a given pixel, we define the dimensionless potential water availability index (wai) for area $m$ under unforced conditions to be

$$
w_{a i}=\ln \left(\frac{P_{m}}{E_{m}} \frac{C A_{m}}{\text { slope }_{m} \Delta x^{2}}\right)(1)
$$

where $P_{m}$ is the annual precipitation, $E_{m}$ is the annual potential evapotranspiration (water evaporated from soil surface and water used by plant via transpiration), $C A_{m}$ is the upstream catchment area, slope $_{m}$ is the local slope and $\Delta x$ is the side length of pixel or cell $m$ for which the analysis is being conducted. $^{3,4}$ The proposed definition given in equation 1 ensures that wai is bounded, even when precipitation equals evapotranspiration. Another advantage is that wai is dimensionless. Values of wai will be high when precipitation is large, upstream catchment area is large, evapotranspiration is low, and the area under analysis is relatively flat. Under these unforced conditions, potentially available water is high at the given location. Conversely in arid, hot, steep headwaters the index values will be low. It should be noted that the time step of one year was chosen to eliminate the effects of soil water storage changes on the value of the index. With the annual time step, measures of precipitation and evapotranspiration used in the equation represent the long-term averages for the basin. Only a Digital Elevation Model (DEM) and raster maps for precipitation and potential evapotranspiration are needed for the area of interest in order to produce a raster map of wai for each pixel within the area.

\section{Crop water productivity index (CWPI)}

As noted above, the proposed CWPI for a given area is defined as the ratio of the value of crop production in that area to the water availability index (wai), as given by equation 1 . More specifically, the crop-water productivity index for a given region $d$ can be written as,

$$
C W P I_{d}=\left\langle\frac{\text { cropval }_{m}}{\text { wai }_{m}}\right\rangle_{d}
$$

where cropval $m$ is the total gross value of all of the crops produced in a given area $m$ in a given year. The brackets indicate spatial averaging of all areas of size $m$ included in the area $d(d \geq m)$. Total crop value reflects crop types and crop-specific yields per unit area, as well as market prices. While the numerator captures the agroecological and economic conditions of the area (the total value of the crops produced in an area is a function of the forcing to the system such as policy action or market conditions and therefore this information is implicit in the $C W P I)$, the denominator captures the potential water availability for the same area. Therefore, agricultural productivity is normalised by the climatic conditions and geographic situation of the area. Isolated from those conditions, difference in productivity between the areas reflects forcing circumstances such as policy action, capital investment, status of market, etc. High values of $C W P I_{d}$ imply more complete use of potentially available water resources. Thus $C W P I_{d}$ calculated using equation 2 gives (a) productivity of water for agricultural uses and (b) the state of water use in 


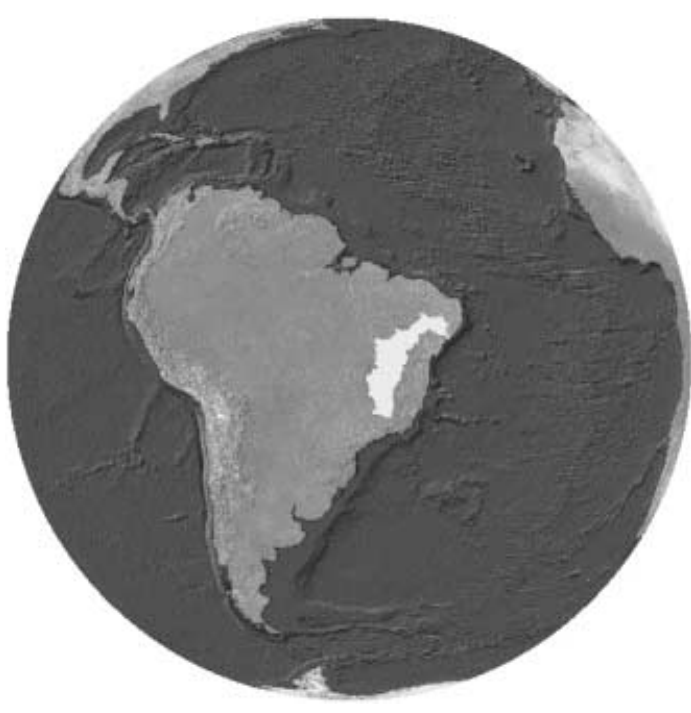

Figure 1 Location of the São Francisco river basin (highlighted area)

relation to potential water availability in different areas of the basin.

While wai can be calculated at an arbitrarily high resolution, information on agricultural production activities is usually available only at municipal or regional resolution. Therefore, calculating $\mathrm{CWPI}_{d}$ requires disaggregating values of cropval into highresolution units comparable to those used to estimate wai, and then reaggregating the ratio of both measures to 'match' the different spatial resolutions of the areas contained in $d$ which are greater than areas of the pixels $m$, and the $d s$ (the municipalities) vary in size. More specifically, cropval, which is reported at area $d$ resolution (i.e. a municipal level), is disaggregated to the resolution of wai (the pixel). The angle brackets in equation 2 indicate that once the ratio is calculated at the wai spatial resolution, it is then aggregated for each area $d$ by simple arithmetic averaging of all pixels $m$ belonging to the area $d$. Disaggregating cropval, calculating the ratio at the wai resolution, and then reaggregating cropval to the municipal level is required because of the strong positively skewed distribution of wai. If wai were first aggregated using spatial averaging over each area $d$ and then $C W P I_{d}$ were calculated, the influence of the greater proportion of wetter pixels in the tail of the distribution would be smoothed out, thereby decreasing the ability of the model to distinguish between areas with different crop-water productivity values.

\section{An application to the São Francisco river basin}

The São Francisco river basin is characterised by a broad range of socioeconomic characteristics, from wealthy areas with high population densities to areas with severe poverty and low population densities. Although much of the land is dedicated to agriculture, forestry and grazing, the basin contains several small and medium-sized urban centres and also encompasses very large urban areas such as the Belo Horizonte metropolitan region in the state of Minas Gerais. Approximately 27 per cent of the land area of the São Francisco river basin is suitable for farming and approximately 3000000 hectares have potential for irrigation, of which around 11 per cent was actually being irrigated in 2003 (Agência Nacional de Águas (ANA) 2004). The São Francisco river is generally characterised as highly undersubscribed, suggesting great potential for the expansion of irrigated agriculture. However, while the basin as a whole might be undersubscribed, this may not be the case for regions within the basin; spatial heterogeneity in the CWPI may help identify areas where expansion of irrigated area may be possible.

\section{Site characteristics, data sources and methodology}

The São Francisco river basin (Figure 1) is an area of more than $630000 \mathrm{~km}^{2}$ and crosses parts of centre west, southeast and northeast Brazil. It is the fourth largest basin in South America and the largest basin to be entirely contained in Brazil. A total of 521 municipalities, with a population of more than 5.68 million (ANA 2004), lie within this area.

The south and southwest have a humid tropical climate with a dry season during the winter. Total yearly rainfall in those areas is often more than $1000 \mathrm{~mm}$. The distributed map of average annual precipitation for the São Francisco river basin (Figure 2) as obtained from the IDIS shows these regions of the basin. The average annual potential evapotranspiration for the same basin is presented in Figure 3. Due to its latitudinal orientation and its length, there is large climatic variation between its southern and northern parts. In contrast to the south and southwest, the northwestern part has a semiarid climate, with annual rainfall of around $500 \mathrm{~mm}$ and high evapotranspiration rates (Figures 2 and 3, respectively). More than half of the total area is in the so-called Drought Polygon, the driest area in Brazil. 


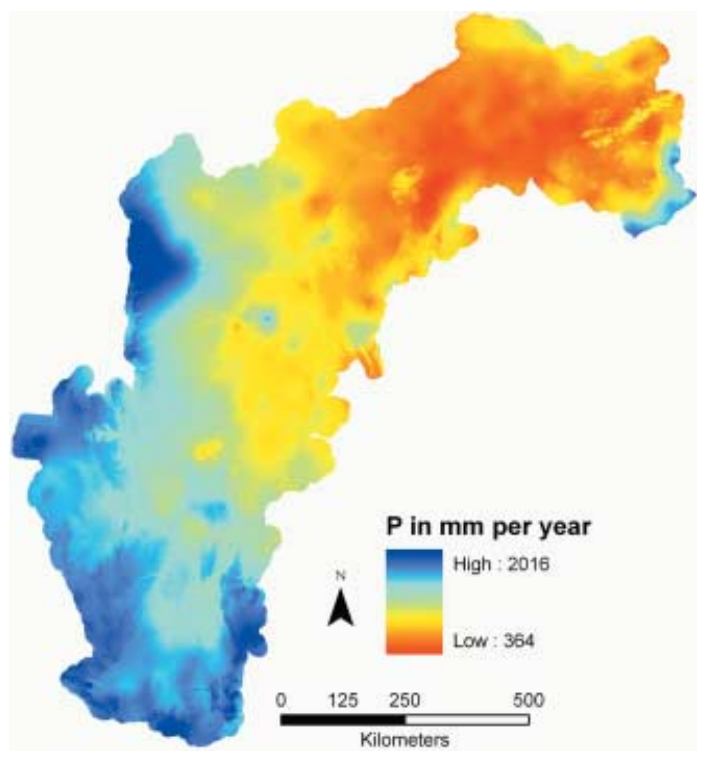

Figure 2 Average annual precipitation in the São Francisco river basin

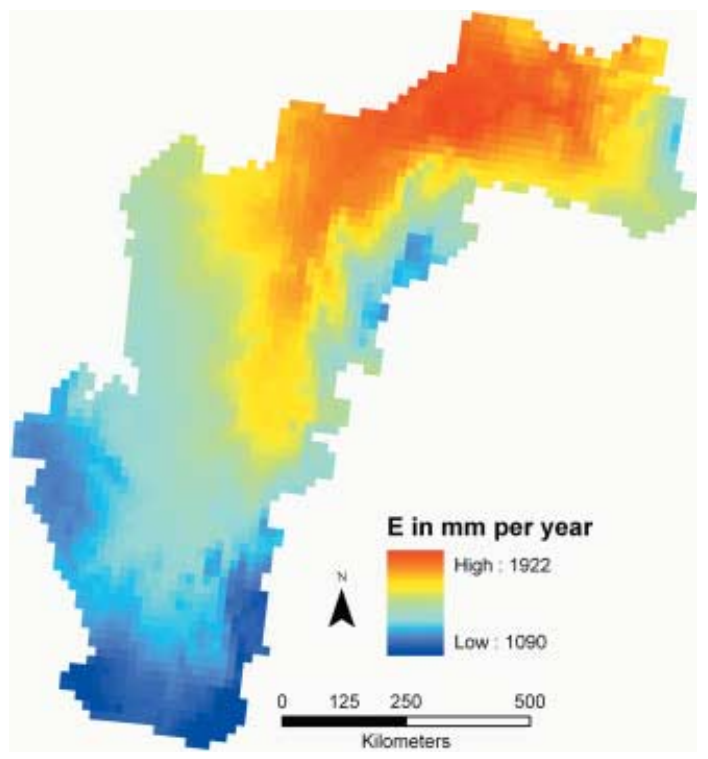

Figure 3 Average annual potential evapotranspiration in the São Francisco river basin

The basin flows northwards from the hilly headwaters in the state of Minas Gerais to the Atlantic Ocean where the main stream meets the Atlantic Ocean between the states of Alagoas and Sergipe.
Figure 4 depicts the steeper slopes in up-basin regions and the flatter areas downstream (methods used to calculate this map are presented below).

The climatic information needed for estimating wai are precipitation and evapotranspiration. The digital elevation model (DEM) is also required to calculate catchments area, local slope and pixel dimension used in equation 1. The source for the relevant precipitation and evapotranspiration data is the World Climate Atlas derived from the Global Historical Climatological Network (GHCN) and compiled for the São Francisco river basin by the International Water Management Institute (IWMI) in its Integrated Database Information System database (IDIS) (IWMI 2002). It is presented at $1-\mathrm{km}$ resolution, and is calculated from data obtained from surface weather stations. As is common, information on the temporal extent (number of years included in the average) and on the temporal resolution of the data used to calculate the averages is not publicly available. Similarly, information on the source, method of interpolation, accuracy or quality of data, is not contained in the metadata for these maps.

The source of the DEM is the Shuttle Radar Topography Mission (SRTM) subset at 90-metre resolution dataset available from the United States Geological Survey (USGS), Earth Resources Observation and Science (EROS) data centre. To derive $C A$ and slope, a $1-\mathrm{km}$ resolution digital elevation model (DEM) of the basin from the IDIS database was used.

The map of mean catchment area and slope, with estimated variances due to possible sensitivity in the DEM, were calculated using a Monte Carlo simulation. As no information was available on the accuracy of the DEM, a sensitivity of 5 per cent was assumed throughout the domain to quantify sensitivity of the derived maps (catchment area and slope) to the accuracy of the DEM. To ensure hydrologic connectivity and convergence of flows to the outlet through the main streams, the original DEM was pre-conditioned with the main drainage network using the terrain preprocessing routines in Arc Hydro Tools (Maidment 2002). One hundred fifty autocorrelated random sensitivity maps were generated using a normal distribution $N\left(0, D^{*} M^{*} 0.05\right)$. Those maps were created using a recursive neighbourhood autocorrelation filter (Table 1) to produce autocorrelation in a map of normally distributed random noise (Beguería S., personal communication 2006).

Each of these autocorrelated random sensitivity maps was then added to the original DEM to produce 

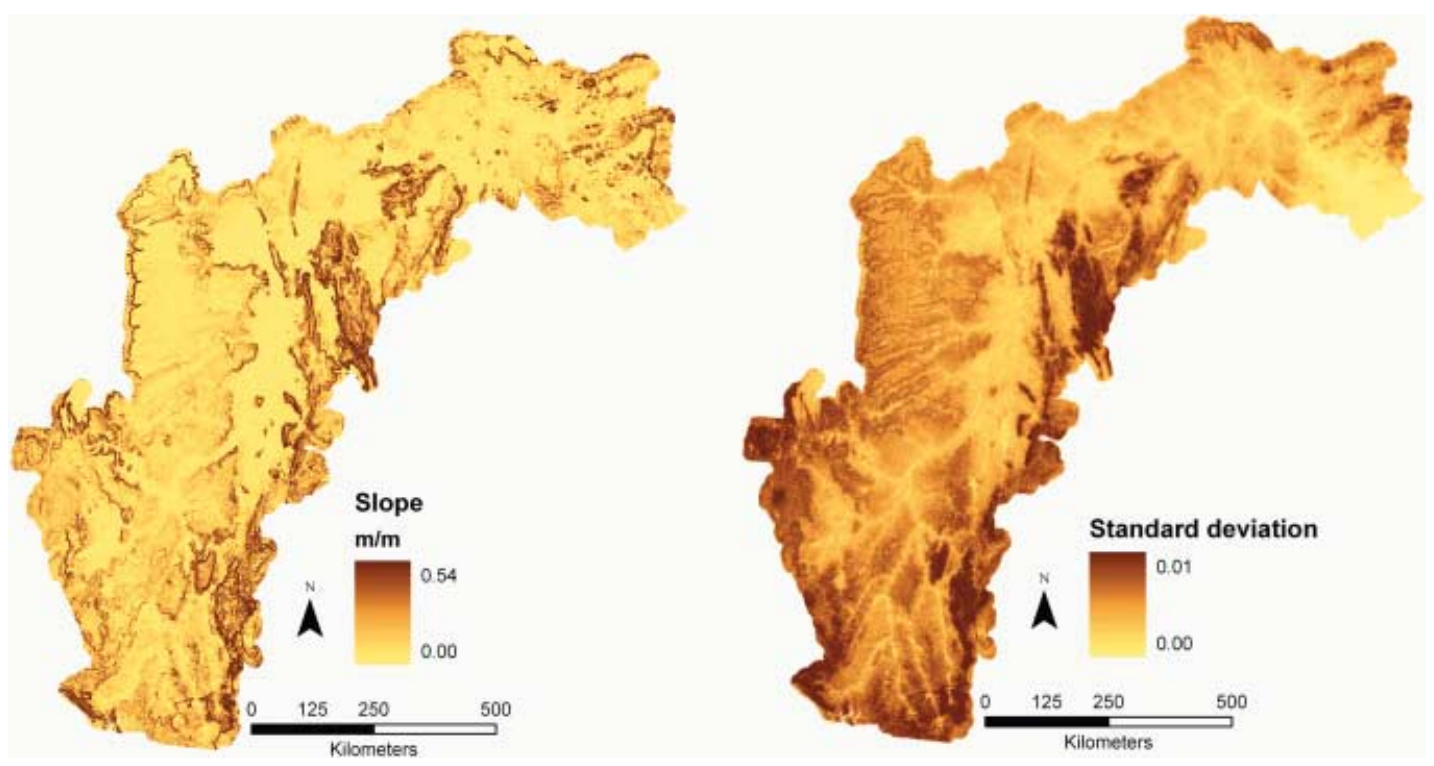

Figure 4 Mean slope with $5 \%$ assumed error in DEM and resulting standard deviation

Table 1 Algorithm for recursive neighbourhood autocorrelation filter

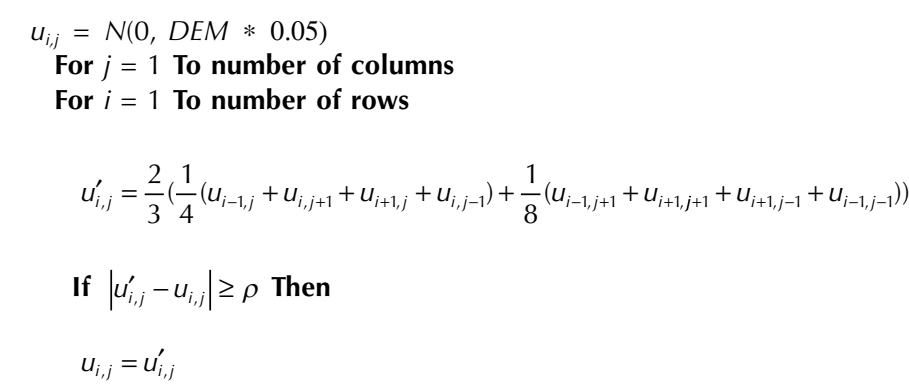

Else

$u_{i, j}^{\prime}=u_{i, j}$

End If

End For

End For

Until $\max \left|u^{\prime}-u\right| \leq \rho$

Where $u$ is the node or cell in the field lattice, subscript $i$ refers to row number increasing from top to bottom and $j$ refers to column number increasing from left to right. The algorithm sweeps column-wise from left to right and top to bottom the random noise field calculating the weighted average of the 8 cells surrounding the $i, j$ cell. The filter is iterated through the random field until all cells have a difference with its neighbour cells less than a user-defined correlation parameter $\rho$ ranging between 0 and 0.25 . 
a perturbed realisation (version) of the original DEM. For each of the perturbed DEM realisation, the slope and catchment area maps were calculated. To calculate the map of upstream catchment area, flow direction for each pixel was found using a steepest slope algorithm. This information was then used to calculate the upslope catchment area by accumulating recursively in each pixel the area of all the pixels draining to it. The final catchment area and slope maps with the estimated sensitivity due to the assumed sensitivity in the original DEM were obtained from the means and standard deviations of the set of 150 realisations of catchments area and slope. The steepest slope algorithm used to calculate the drainage network is extremely sensitive to perturbation in the DEM (Quinn et al. 1991). Catchment area maps derived from the 150 DEM realisations show a large variance due to many different possible drainage connectivity configurations, many of which did not have full connectivity to the outlet. For tackling this issue, the mean DEM was again conditioned with the river network to ensure full hydrologic connectivity. As the hydrological connectivity is externally forced through the DEM conditioning process, it does not depend on the DEM accuracy, and therefore the resulting catchment area map was considered invariant under DEM sensitivity conditions and thus not included in the sensitivity analysis presented below.

Data for the total value for annual crop production were taken from the 2004 Agricultural Municipal Production (PAM) data sets (IBGE 2005). The PAM data contain annual information on planted area, harvested area, quantity produced and the value of production for 35 annual and perennial crops. A time-invariant set of municipal boundaries have been constructed to follow changes in key agricultural variables over time (Torres et al. 2006).

\section{Results and discussion}

Due to the climatic and topography contrasts, the potential availability of water in the São Francisco river basin has large spatial variations, with likely impacts on the spatial patterns of agricultural production and agricultural income. Figure 5 shows the spatial distribution of the total value for crop production in 2004 at the municipal level in (2004) Brazilian Reais. These data will be interpreted below in the context of the water availability index and the crop-water productivity index.

The resulting map of the potential water availability index (wai) is presented in Figure 6. As expected,

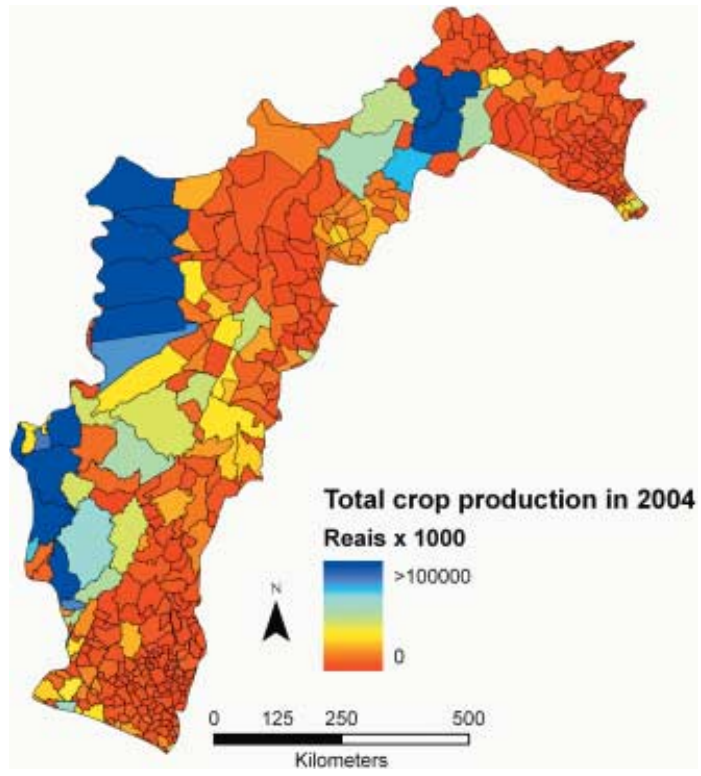

Figure 5 Spatial distribution of the total value for crop production in 2004 at the municipality level

areas along the valley floors and in the wetter south and western parts of the basin with higher precipitation and moderate evapotranspiration (Figures 2 and 3, respectively) have higher potential water availability (darker blue portions of Figure 6). In contrast, reddish portions of Figure 6 correspond to areas with low potential water availability; these are found in the relatively drier northern part of the basin and in the mountain ranges with steep slopes and comparatively small contributing areas (Figure 4).

Figure 7 a shows the resulting crop-water productivity index, on a per square metre area basis, averaged over each municipality (equation 2). Figure $7 b$ illustrates the high-resolution CWPI on a per square metre basis, averaged to the pixel level. Higher CWPI scores (the darker blue regions of Figures $7 \mathrm{a}$ and $7 \mathrm{~b}$ ) are found in the northern and western regions of the basin. Note that for a given value of wai, a higher value for cropval will lead to a higher CWPI. However, because cropval is normalised by wai, high CWPI values are likely to correspond to areas where productivity of water has increased due human interventions (e.g. the installation of irrigation systems). The CWPI value is high because in such areas the cropval is large (high productivity and trade) relative to the potentially available water, 


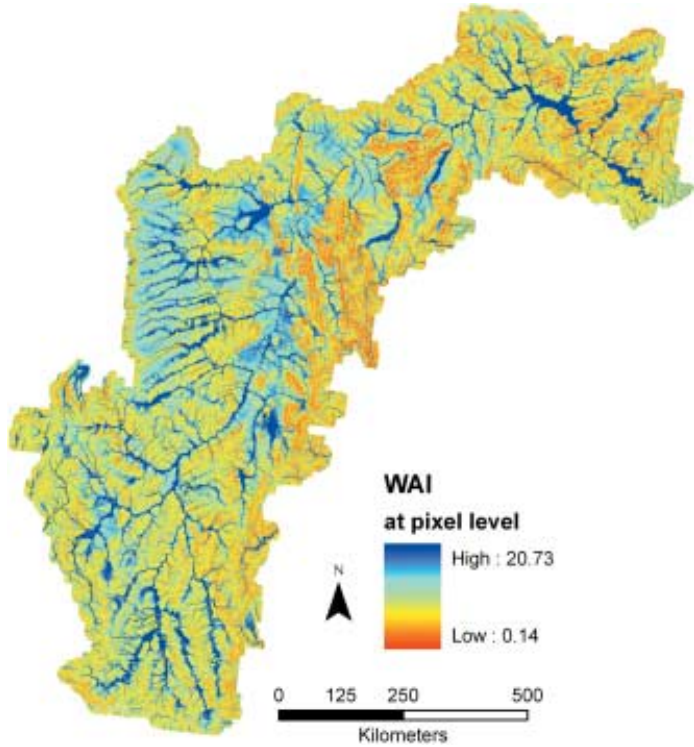

Figure 6 wai at pixel level under unforced conditions in the São Francisco river basin indicating a high level of forcing or development. Thus cropval by itself may not be a useful indicator to quantify the level of productive use of potentially available water resources, but in combination with wai it can be a useful indicator to evaluate (a) agricultural productivity per unit of water actually applied (some fraction of potentially available water) and (b) the fraction of potentially available water from direct precipitation and from the river passing through the area that is applied to the crops in different areas of the basin.

To be useful, the index must display spatial variability - Figures $7 \mathrm{a}$ and $7 \mathrm{~b}$ confirm our proposed index has this characteristic. A range of values of the proposed CWPI emerged from our analysis, and one can break this range of values into two dimensions, one representing a range of values for total crop production and another representing a range of values for the potential water availability index. ${ }^{5}$ Table 2 does so, dividing values of wai (the CWPI denominator) into 'high' and 'low' categories on the vertical axis, and dividing values of cropval (the numerator of the CWPI) into 'high' and 'low' categories on the horizontal axis.

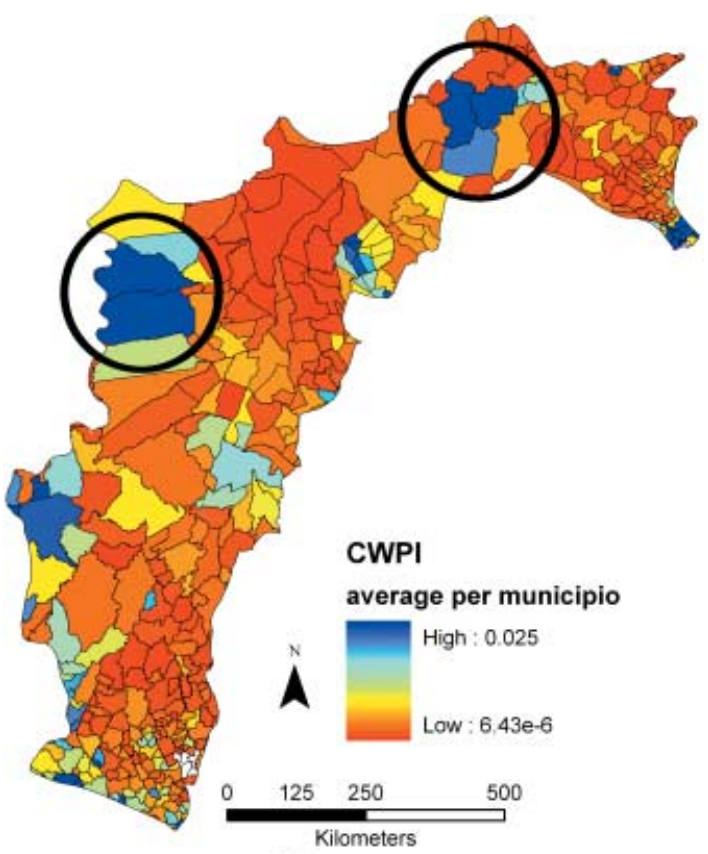

(a)

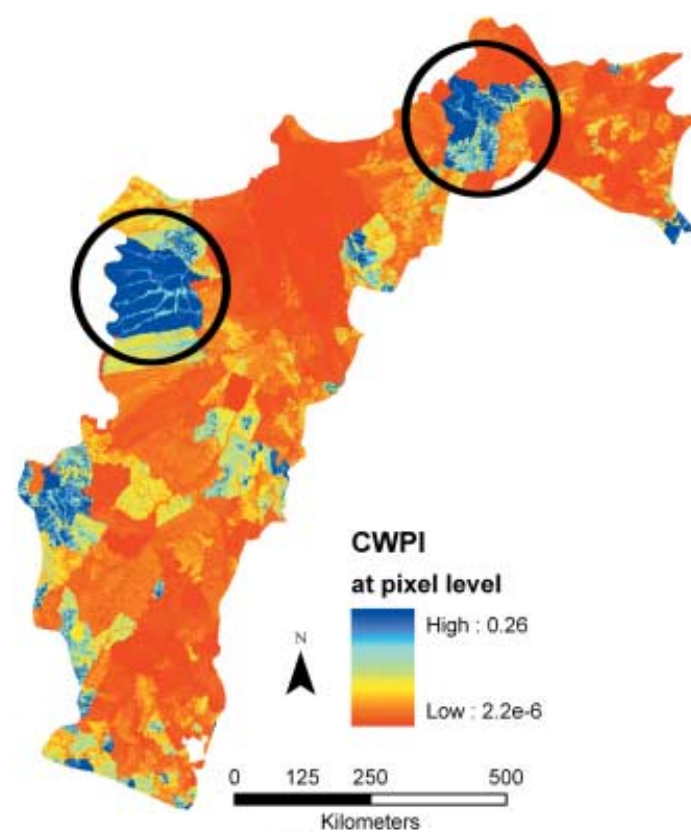

(b)

Figure $7 \quad C W P I$ at (a) the municipality and (b) the pixel level 
Table 2 CWPI interpretation matrix

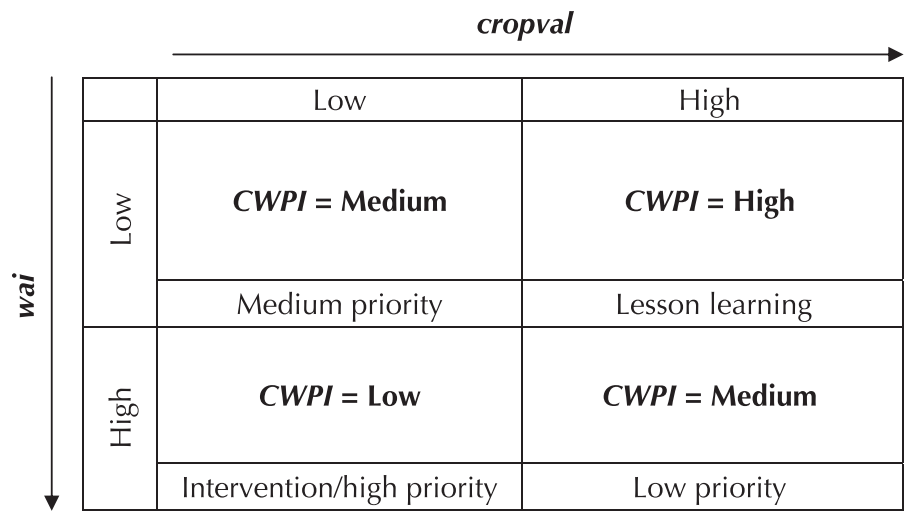

Low CWPI scores occupy the lower-left corner of Table 2 where high measures of water availability and low measures of the value of crop production coincide. One would expect these low CWPI outcomes to occur adjacent to rivers and in high-precipitation regions where the value of aggregate output is low. However, Figure $7 \mathrm{~b}$ indicates that a very large number of municipalities throughout the São Francisco river basin fall into this low CWPI category. There are several explanations. First, most of these 'red' municipalities have low proportions of area dedicated to high-value crops and even smaller proportions under irrigated agriculture. Second, and related, most of these low CWPI municipalities are not located near major cities or market centres. Third, and also related, resource-poor small-scale agriculturalists tend to be more prevalent in these municipalities than in others.

At the other extreme, high values of the CWPI index occupy the upper-right corner of Table 2. Municipalities occupying this cell have relatively low amounts of available water but relatively high values of total crop production. One would expect these high-cropval/low-wai cases to emerge in areas where irrigated agriculture is most prevalent. Indeed, this is the case. The two major clusters of 'blue' municipalities in Figure 7 are precisely where major investments in water conveyance infrastructure and irrigation have been made. For example, the cluster at the upper-right of Figure $7 \mathrm{a}$ is the PetrolinaJuazeiro region, site of intensive public and private sector investments in irrigation and high-valued annual and perennial crops dating back more than two decades. The cluster at the western side of the basin is the Barreiras region, which is the centre of another major irrigation project developed in the basin of the Rio Grande. The region is a large producer of corn, soybean, fruits and coffee among other products. The city of Barreiras is the most important economic centre in the region that received large investments in providing a well articulated market.

Medium-level values for CWPI occupy two cells in Table 2, the low-low and the high-high cells, and these 'yellow' and 'greenish' municipalities in Figure $7 \mathrm{a}$ are distributed more or less uniformly throughout the São Francisco river basin, with the exception of the 'solid red' zone in the middle of the basin. A glance back at Figure 2 helps place this group of municipalities into one of two cells in Table 2 . Those in the high rainfall areas in the southern and central-eastern portions of the basin will likely fall into the high-high cell; farmers in these municipalities have been able to use rainfall and run-off to generate relatively high values of total crop production. Medium-level municipalities located in low rainfall and low slope areas in Figure 7a suffer from low aggregate values of crop production.

Several policy-relevant messages emerge from an interpretation of the CWPI. First, access to water (by the definition of potential water availability adopted here) does not correlate well with value of crop production. There are many municipalities in the São Francisco river basin which by virtue of their locations in the basin have relatively more water available than other municipalities, yet they have not been able to effectively use that water to increase the value of agricultural production, either because the proportion of irrigated land is small or irrigation is being applied to low-valued crops, or 
both. The existence of a wide range of values of the index throughout the basin is an indication that there is room for more efficient access to water or that other factors can be used as a substitute for water to increase agricultural productivity. Second, most municipalities in the São Francisco river basin registered relatively low values of crop-water productivity. This is primarily attributable to the narrow and low value/low productivity nature of the product mix options available to rainfed agriculturalists in these areas. Third, irrigation matters greatly in determining the value of agricultural output; those (relatively few) municipalities that have managed to supplement precipitation and make the other investments required to establish and maintain high-valued production systems have very high crop-water productivity index values. Finally, several relatively large areas exist within the São Francisco river basin that are very 'red', i.e. clusters of municipalities which, for probably a number of reasons, have not effectively tapped their water resources for agricultural purposes.

\section{Sensitivity analysis}

Sensitivity in input variables such as precipitation, evapotranspiration and the value of crop production can greatly affect the water availability index (wai) and the $C W P I_{d}$. How the sensitivity in input data propagates to the output data is of great interest in assessing the reliability of the indices, and of the policy guidance derived from them. Propagation of sensitivity in the input data to the output of the model is presented here to evaluate the sensitivity of the results to sensitivity in input data.

A sensitivity of 5 per cent in all of the data is assumed for the purpose of the analysis. The covariance of sensitivity for all the variables is considered stationary and equal to the covariance of a subset of 100 sensitivity points randomly sampled throughout the domain for different variables.

Calculating the propagation of uncertainty in input data to output data can be greatly simplified by using a first-order Taylor series expansion (Heuvelink 1998). In this method, a given function is approximated by taking its tangent around the mean of the inputs. Using this linearisation process, the output of the function can be easily evaluated for small changes in the inputs, given by the variance/ covariance of the sensitivity. The variance of the function output, given the uncertainty (sensitivity) in the inputs, is approximated by $\sigma^{2} \approx \sum_{i=1}^{k} \sum_{j=1}^{k}\left\{C_{i j} \frac{\partial f(\bar{b})}{\partial \bar{b}_{i}} \frac{\partial f(\bar{b})}{\partial \bar{b}_{j}}\right\}$

where $i=1, \ldots, k, j=1, \ldots, k$ represent each of the $k$ variables $(b), C_{i, j}$ is the variance/covariance between pairs of variables, $f$ is the function (in our case the CWPI function) evaluated with respect to variables $\bar{b}=\left\{b_{1}, b_{2}, \ldots, b_{k}\right\}$.

A first-order Taylor expansion like the one presented would expand to a number of terms equal to the square of the parameters involved in the analysis, but typically many of the inputs are uncorrelated so the terms with non-significant covariance would vanish. In the present case, we assume stationary covariance in space (independent of location $i$ ), drop the variance/covariance terms involving the catchment area (which was considered not to propagate the sensitivity in the DEM as the drainage network is externally imposed), and use symmetry of the covariance matrix to give the final expression for the expansion used to evaluate the propagation of the sensitivity in the input data to the CWPI as

$$
\begin{aligned}
& \partial_{i}^{2} \approx 2\left(\begin{array}{l}
C_{\text {cropval }, E} \frac{\partial C P W I}{\partial \text { cropval }} \frac{\partial C P W I}{\partial E_{i}} \\
+C_{\text {cropval }, S} \frac{\partial C P W I}{\partial c r o p v a l_{i}} \frac{\partial C P W I}{\partial S_{i}} \\
+C_{\text {cropval }, P} \frac{\partial C P W I}{\partial c r o p v a l_{i}} \frac{\partial C P W I}{\partial P_{i}} \\
+C_{E, S} \frac{\partial C P W I}{\partial E_{i}} \frac{\partial C P W I}{\partial S_{i}}+C_{E, P} \frac{\partial C P W I}{\partial E_{i}} \frac{\partial C P W I}{\partial P_{i}} \\
+C_{S, P} \frac{\partial C P W I}{\partial S_{i}} \frac{\partial C P W I}{\partial P_{i}} \\
+\sigma_{\text {cropval }, i}^{2}\left(\frac{\partial C P W I}{\partial c r o p v a l_{i}}\right)^{2}+\sigma_{E, i}^{2}\left(\frac{\partial C P W I}{\partial E_{i}}\right)^{2} \\
+\sigma_{S, i}^{2}\left(\frac{\partial C P W I}{\partial S_{i}}\right)^{2}+\sigma_{P, i}^{2}\left(\frac{\partial C P W I}{\partial P_{i}}\right)^{2}
\end{array}\right)
\end{aligned}
$$

Here $C_{\text {cropval, }, E}$ represents the covariance between cropval and potential evapotranspiration (E) and $\sigma_{\text {cropval }, i}^{2}$ represents the variance of cropval at location $i$. The same notation protocol is used for other covariance and variance terms.

The maps with the spatial distribution of the standard deviations for CWPI resulting from an assumed sensitivity of 5 per cent in the input data are shown in Figure 8, aggregated at the pixel resolution and in Figure 9 aggregated at the municipality resolution. As can be seen in the figures, the uncertainty 


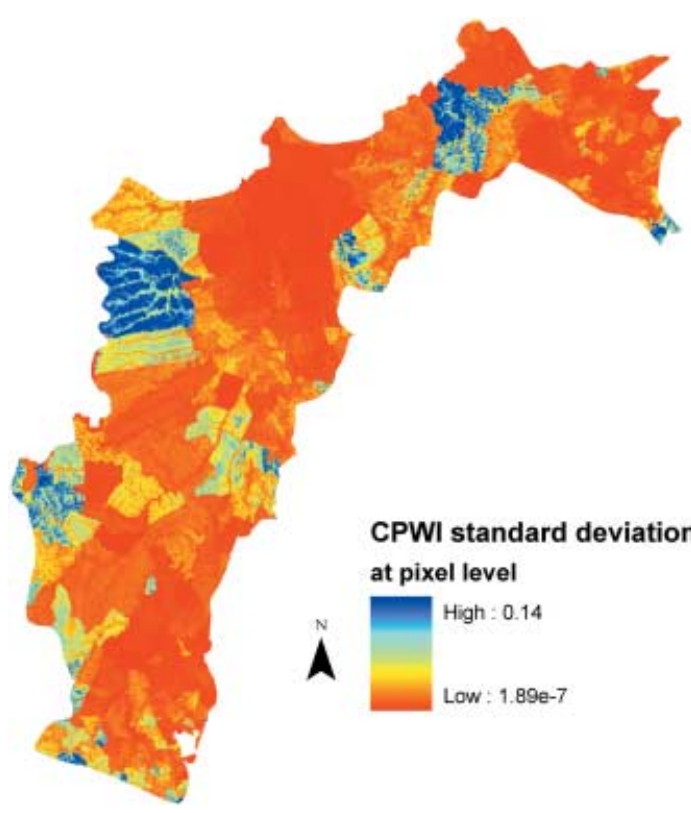

Figure 8 Standard deviation of CWPI averaged at the pixel resolution

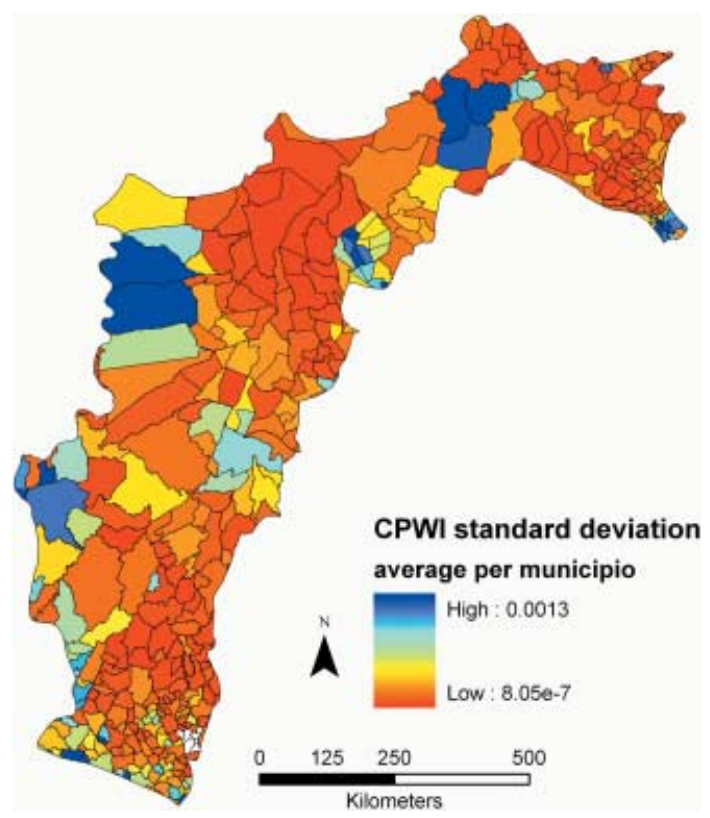

Figure 9 Standard deviation of CWPI averaged at municipality resolution

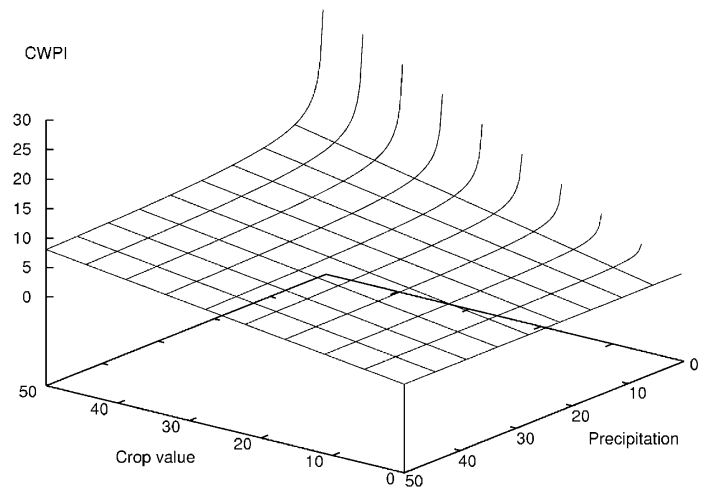

Figure 10 Changes in CWPI with slope and crop value

in the output data is not randomly distributed in space. A large part of the sensitivity distribution is a result of the functional form of the index. Figure 10 is a partial reproduction of the CWPI function against two variables, crop value and precipitation. As can be seen in the figure, large absolute derivatives of the CWPI are found for small values of precipitation and large values of the value of total crop production. These portions with high derivatives are the most sensitive part of the function domain where even small variations in the input variable result in large differences in the output data. This is consistent with the results shown in Figures 8 and 9, where the values of the highest standard deviation in CWPI are mainly found in areas with high annual crop production values per unit area.

From an analysis of the effects of sensitivity in different variables on CWPI function, it follows that care has to be taken when interpreting CWPI for areas with high crop production values. This would also imply that more effort in collecting and treating annual crop value data is required. Fortunately, the areas of high CWPI values may not be currently targeted for (perhaps additional) water management interventions.

\section{Conclusions}

Increasing water productivity in agriculture is essential for meeting future food needs. However, we currently lack practical tools for measuring water productivity in rural areas. This paper presented a crop-water productivity index for large water basins using readily available low-resolution data. The index is a ratio of the value of annual crop production to a dimensionless potential water availability index. 
The index is transferable, permits direct comparison between different basins and is simple to calculate. The algorithm can also be used to quantify and analyse spatial input information uncertainty; such information can be useful to decisionmakers in assessing the relative risks associated with alternative, site-specific agricultural investments. We calculate the index for each of the 469 municipalities that comprise the São Francisco river basin in Brazil. Access to water does not correlate well with value of crop production. There are many municipalities in the São Francisco river basin which by virtue of their locations in the basin have relatively more water available than other municipalities, yet they have not effectively used that water to increase the value of agricultural production. This result strongly suggests that while access to water may be a necessary condition for boosting the value of aggregate crop production, other factors (e.g. access to markets for high-valued products) may be equally important in achieving this objective. Most municipalities in the São Francisco river basin registered relatively low values of crop-water productivity and irrigation matters greatly in determining the value of agricultural output; the relatively few municipalities that have substantially supplemented precipitation have very high crop-water productivity index values. There is a broad array of CWPI values scattered throughout the basin, demonstrating that agronomic and market options exist in many parts of the São Francisco river basin, regardless of climatic situations. Several relatively large clusters of municipalities have not tapped their water resources for agricultural purposes; in an increasingly water-scarce world, policymakers should look to areas like these as the potential bread-baskets of the next 50 years.

Analyses of the effects of information uncertainty on the crop-water productivity index suggest that, due to the functional relationships between the variables included in the index, we should take special care in interpreting the results for municipalities with very high values of total crop production. Small errors in the numerator can cause large changes in the value of the CWPI.

\section{Acknowledgements}

This research project is sponsored in part by the Challenge Program on Water and Food (CPWF) of the Consultative Group on International Agricultural Research (CGIAR), in collaboration with the International Water Management Institute (IWMI). We also gratefully acknowledge financial support from the Center for Natural Resources Policy Analysis at the University of California, Davis, and the Empresa Brasileira de Pesquisa Agropecuaria (Embrapa), as well as the assistance of Katherine Laumas, Erik Lue and Pedro Gasparinetti for assistance in compiling and interpreting data. The opinions expressed in this paper are not necessarily those of the supporting agencies.

\section{Notes}

1 The geographic term 'extent' is used to describe the geographical bounding measure for which the spatial analysis is conducted; e.g. in this case the spatial extent of analysis is the entire São Francisco river basin. In contrast, the term 'resolution' is used to characterise the smaller elements, or units of observation, within the extent for which spatial analysis is conducted; e.g. in this case, the resolution for the agricultural analysis is the municipality, and the resolution for the hydrologic analysis is the square kilometre.

2 Local is the length scale of the each spatial unit of observation, e.g. one kilometre on-a-side pixel.

3 Taking the natural log of the ratio dampens the large differences between wet and dry cells.

4 An alternative water availability index might use the difference between the precipitation and evapotranspiration in its numerator but when they are equal that water availability index would go to zero and this would cause the ratio of crop value to the alternative water availability index to be unbounded.

5 As noted above, alternative aggregation methods and spatial resolutions of analysis were used in calculating our proposed CWPI; the values associated with these alternative index measures were highly correlated, so our interpretation is robust across the various methods and units of analysis examined here.

\section{References}

Abdullaev I and Molden D 2004 Spatial and temporal variability of water productivity in the Syr Darya Basin, central Asia Water Resources Research 40 W08S02, doi:10.1029/ 2003WR002364

Agência Nacional de Águas (ANA) 2004 Strategic action program for the integrated management of the São Francisco river basin and its coastal zone Final Report ANA in collaboration with GEF, UNEP and OAS

Ahmad M D, Masih I and Turral H 2004 Diagnostic analysis of spatial and temporal variations in crop water productivity: a field scale analysis of the rice-wheat cropping system of Punjab, Pakistan Journal of Applied Irrigation Science 39 43-63

Bastiaanssen W G M 1999 Satellite remote sensing for estimating productivities of land and water International Journal of Water Resources Development 15 181-94

Beven K J and Kirkby M J 1979 A physically-based variable contributing area model of basin hydrology Hydrological Science Bulletin 24 43-69 
Dunne T and Leopold L B 1978 Water in environmental planning Freeman, New York

Florinsky I V, Eilers R G, Manning G R and Fuller L G 2002 Prediction of soil properties by digital terrain modelling Journal of Environmental Modelling \& Software 17 295-311

Gómez-Plaza A, Martínez-Mena J, Albaladejo J and Castillo V M 2001 Factors regulating spatial distribution of soil water content in small semiarid catchments Journal of Hydrology 253 211-26

Heuvelink G B M 1998 Error propagation in environmental modelling Research monographs in GIS series, Taylor \& Francis, London

Hewlett J D and Troendle C A 1967 Factors affecting the response of small watersheds to precipitation in humid areas Proceedings of International Symposium on Forest Hydrology Pergamon, Pennsylvania State University 275-90

Hjerdt K N, McDonnell J J, Seibert J and Rodhe A 2004 A new topographic index to quantify downslope controls on local drainage Water Resources Research 40 W05602, doi: 10.1029/2004WR003130

IBGE 2005 Municipal Agricultural Production (PAM) Instituto Brasileiro de Geografiae Estatística (http://www.sidra. ibge.gov.br/bda/acervo/acervo2 .asp? $\mathrm{e}=\mathrm{v} \& \mathrm{p}=\mathrm{PA} \& \mathrm{z}=\mathrm{t} \% \mathrm{O}=10$ ) Accessed 21 January 2006

IWMI 2002 Integrated Database Information System (IDIS) International Water Management Institute (http://dw.iwmi.org) Accessed 3 January 2006

Kassam A and Smith M 2001 FAO methodologies in crop water use and crop water productivity Expert meeting on water productivity FAO, Rome 3-5 December 2001

Lee D and Barret C eds 2001 Tradeoffs or synergies? Agricultural intensification, economic development and the environment $\mathrm{CABI}$, Wallingford

Lobell D B, Asner G P, Ortiz-Monasterio J I and Benning T L 2003 Remote sensing of regional crop production in the Yaqui Valley, Mexico: estimates and uncertainties Agriculture, Ecosystems \& Environment 94 205-20

Maidment D R 2002 Arc hydro: GIS for water resources ESRI Press, Redlands CA
Merot P, Ezzahar B, Walter C and Aurousseau P 1995 Mapping waterlogging of soils using digital terrain models Hydrological Processes 9 27-34

Merot P et al. 2003 Testing a climato-topographic index for predicting wetlands distribution along an European climate gradient Ecological Modelling 163 51-71

Molden D 1997 Accounting for water use and productivity International Irrigation Management Institute System Wide Initiative for Water Management (SWIM) paper 1

O'Loughlin E 1981 Prediction of surface saturation in catchments and their relations to soil and topographic analysis Water Resources Research 22794

Quinn P, Beven K, Chevallier P and Planchon O 1991 The prediction of hillslope flow paths for distributed hydrological modelling using digital terrain models Hydrological Processes 5 59-79

Rosegrant M W, Msangui S, Sulser T and Ringler C 2006 Future scenarios for agriculture: plausible futures to 2030 and key trends in agricultural growth Background paper prepared for the World Development Report 2008, International Food Policy Research Institute, Washington DC

Torres M, Vosti S A, Bassoi L H, Howitt R, Maneta M, Pfeiffer L, Rodrigues L, Wallender W W and Young J 2006 Identifying the boundaries of the São Francisco River Basin and the set of municípios that comprise it São Francisco River Basin Research Team working paper UC Davis, revised 6 July 2006

Western A W, Grayson R B, Blöschl G, Willgoose G R and McMahon T A 1999 Observed spatial organization of soil moisture and its relation to terrain indices Water Resources Research 35 797-810

World Bank 2007 World development report 2008: agriculture for development Document number 35999, The World Bank, Washington DC

Zwart S J and Bastiaanssen W G M 2004 Review of measured crop water productivity values for irrigated wheat, rice, cotton and maize Agricultural Water Management 69 115-33 